\title{
Balancing health worker well-being and duty to care: an ethical approach to staff safety in COVID-19 and beyond
}

\author{
Rosalind J McDougall (D) ,' Lynn Gillam, ${ }^{1,2}$ Danielle Ko, ${ }^{3,4}$ Isabella Holmes (D) ,' \\ Clare Delany ${ }^{2,5}$
}

${ }^{1}$ Melbourne School of

Population and Global Health, University of Melbourne, Melbourne, Victoria, Australia ${ }^{2}$ Children's Bioethics Centre, Royal Children's Hospital, Parkville, Victoria, Australia ${ }^{3}$ Department of Palliative Care, Austin Health, Heidelberg, Victoria, Australia

${ }^{4}$ Department of Quality and Patient Safety, Austin Health, Heidelberg, Victoria, Australia ${ }^{5}$ Department of Medical Education, University of Melbourne, Melbourne, Victoria, Australia

Correspondence to Dr Rosalind I McDougall, Melbourne School of Population and Global Health, The University of Melbourne, Melbourne, VIC 3010, Australia; rmcdo@unimelb.edu.au

Received 4 June 2020 Revised 7 September 2020 Accepted 11 September 2020 Published Online First 25 September 2020
A) Check for updates

(c) Author(s) (or their employer(s)) 2021. No commercial re-use. See rights and permissions. Published by BMJ.

To cite: McDougall RJ, Gillam L, Ko D, et al. $J$ Med Ethics

2021;47:318-323.

\section{ABSTRACT}

The COVID-19 pandemic has highlighted the risks that can be involved in healthcare work. In this paper, we explore the issue of staff safety in clinical work using the example of personal protective equipment (PPE) in the COVID-19 crisis. We articulate some of the specific ethical challenges around PPE currently being faced by front-line clinicians, and develop an approach to staff safety that involves balancing duty to care and personal well-being. We describe each of these values, and present a decision-making framework that integrates the two. The aim of the framework is to guide the process of balancing these two values when staff safety is at stake, by facilitating ethical reflection and/or decision-making that is systematic, specific and transparent. It provides a structure for individual reflection, collaborative staff discussion, and decision-making by those responsible for teams, departments and other groups of healthcare staff. Overall the framework guides the decision maker to characterise the degree of risk to staff, articulate feasible options for staff protection in that specific setting and identify the option that ensures any decrease in patient care is proportionate to the increase in staff well-being. It applies specifically to issues of PPE in COVID-19, and also has potential to assist decision makers in other situations involving protection of healthcare staff.

\section{INTRODUCTION}

The COVID-19 pandemic has highlighted forcefully the fact that healthcare work can be risky. The safety of healthcare personnel has become a pressing issue in the context of a highly contagious virus that has killed a substantial number of healthcare workers. The shortages of personal protective equipment (PPE) in particular have generated media headlines bringing this issue to the front of public consciousness: 'Coronavirus treatment doctors report trauma, threats over lack of PPE in hospitals', 'NHS staff making masks from snorkels amid PPE shortages', 'How did the U.S. end up with nurses wearing garbage bags?'. 3 As the pandemic evolves, so too do the specific issues around PPE in different countries and care settings, with changing PPE standards and levels of supply.

Ethical questions about staff protection are not new. Previous epidemics including SARS, Ebola and HIV/AIDS, have raised the ethical issue of healthcare staff safety in the context of an infectious disease outbreak. ${ }^{4}$ The consensus in those epidemics was that healthcare staff had some duty to treat, because appropriate safety measures were taken to protect staff, resulting in a generally low risk of infection. ${ }^{5}$

However, there are features of the COVID-19 crisis that are different to previous epidemics. The shortage of basic PPE such as masks, gloves and gowns in so many settings is an important difference. For health systems in high-income countries, such shortages are unprecedented in health professionals' experience. In addition, in the current pandemic, some form of PPE would ideally be available for all professional caregiving interactions meaning that the number of workers affected is vast.

Inadequate availability of PPE for healthcare workers raises important ethical questions at a health system level about staff safety, and these have been a focus of ethics work in this area to date. What are the obligations of governments to provide PPE ${ }^{6}$ Under what social structural circumstances would healthcare workers have an obligation to treat patients with COVID-19? ${ }^{7}$ How should limited PPE be distributed among healthcare services and within organisations? ${ }^{8}$ In Australia, for example, many general practitioners were unable to access PPE, with priority given to hospitals in allocating equipment from the national stockpile. ${ }^{9-11}$

However, there are also a set of clinical ethics questions arising in relation to PPE for health professionals working in the context of COVID19. By 'clinical ethics questions', we mean microlevel challenges faced by individual clinicians or teams in the context of their clinical work. These are ethical questions clinicians are asking as they navigate patient care in the pandemic, for example: To conserve PPE, should we decrease frequency of nursing care for this patient? Am I entitled to more PPE than recommended, to protect my vulnerable loved one? Should we delay resuscitation to don PPE? Both individual clinicians and leaders of teams are encountering specific ethical challenges around staff safety as they care for patients in the current pandemic. Clinical ethics questions are often interlinked with systemic or organisational ethical issues. Clinicians and teams are faced with navigating their immediate current circumstances and, at the same time, advocating for and/or assisting the hospital to formulate an institutional response, which often lags behind.

In this paper, we focus on clinical ethics questions. We use clinical ethics questions that arise in relation to PPE in the COVID-19 crisis to explore the issue of healthcare staff protection in clinical 
work. We articulate some of the specific challenges around PPE currently being faced by front-line clinicians, and develop an approach to staff safety that aims to balance duty to care and personal well-being. It is important to note that the specific cases we outline reflect our experience as hospital-based clinical ethicists in Australia, where PPE shortages have been much less acute for hospital staff than in many other countries and the healthcare system has not been overwhelmed by high numbers of COVID-19 cases. However, the types of ethical questions that we articulate and the approach to analysis that we advocate is applicable in other settings. We offer a framework of steps and associated questions for structuring clinical ethics decisionmaking about PPE in the COVID-19 crisis, and potentially for clinical ethics decision-making about healthcare staff safety in situations beyond the current pandemic.

\section{What is different about staff protection in the COVID-19 pandemic?}

Health professionals are exposed to risks of various kinds in doing their jobs, but usually these can be well managed. Healthcare workers wear protective gear when taking X-rays, get vaccinated against influenza, follow infectious disease protocols when treating patients with communicable diseases and can be treated prophylactically where there is no effective vaccine (for example in HIV exposure). Usually, clinicians have the information and resources they need to appropriately protect themselves while still providing optimal care for patients.

In the COVID-19 pandemic, however, simultaneously achieving both appropriate staff protection and high quality patient care has become more difficult. In the COVID-19 situation, these two values - staff protection and patient care-cannot both be optimised due to the virus itself as well the conditions the pandemic has created.

The infectivity and route of transmission of the disease (in the air via droplets and also by contact with contaminated surfaces) means that adequate protection is harder in relation to COVID-19 compared with other infectious diseases. Given that many people infected with COVID-19 can be asymptomatic, the source of risk is not always readily identifiable. To date, there is not a quick, reliable and universally available test to show which patients carry COVID-19 and which do not, meaning it is not currently feasible to ascertain the status of all patients presenting for healthcare services. The serious health outcomes for infected healthcare workers and potentially their family and household members through accidental transmission heightens the burdens. ${ }^{12}$

Most importantly, the extent of the outbreak means that there is inadequate PPE in many settings, including in countries with advanced well-resourced healthcare systems. The features of the virus described above, coupled with the limited scientific understanding of COVID-19, means that inadequate PPE results in serious risks and burdens for healthcare workers. Finally, the COVID-19 situation is different to previous infectious disease outbreaks given the scale of the pandemic which in some countries has required large-scale reallocation of staff to other roles. ${ }^{13}$

\section{New clinical ethics questions}

These features of the COVID-19 pandemic are creating new clinical ethics questions for clinicians working during the crisis. These can sometimes be emotionally challenging, even frightening, ethical decisions to have to make, when one's own safety is involved and that of one's family.
In our experience, the clinical ethics questions that clinicians are navigating in relation to staff protection during the COVID-19 situation include the following:

- Should we decrease patient care in order to conserve PPE?

- What should I do when the PPE provided is inadequate for the task?

- Should I abstain from working to protect my family?

- Can I use more PPE than recommended, to protect my vulnerable family member at home?

- Is wearing the PPE ethically required when it is inhibiting my relationship with a low-risk patient?

- Should we delay resuscitation to don PPE?

Cases illustrating each of these ethical questions are provided in table 1 . These questions and cases are based on our experience as clinical ethicists in hospitals in the Australian setting. We have altered and amalgamated cases so that they reflect real issues but do not describe specific individuals.

\section{Balancing values}

Generally in clinical ethics decision-making, choosing between different options involves balancing different values, obligations or principles. ${ }^{14}$ One possible pathway of action may promote one value at the expense of a conflicting value. For example, in case 6 involving the emergency department team, delaying resuscitation to don additional PPE promotes staff safety but is problematic from the perspective of maximising the patient's chances of recovery.

There is no formula for balancing different values in clinical ethics. Reasonable people working from the same principles and using the same information can reach different conclusions or outcomes when they balance values. This is one reason why clinical ethics decisions are best made in consultation with others. In our view, it is more rigorous to balance values through discussion than through individual reflection. In the COVID-19 pandemic, to the greatest extent practicable, clinicians should not be left to make clinical ethics decisions alone.

Balancing involves thinking through the extent to which the relevant values will be affected in each of the different possible action options. It involves explaining the values' relative ethical weight or significance in the specific circumstances, so that options can be compared and a decision made. The aim is that the reasons underlying the final judgement can be articulated to the greatest possible extent, making the decision-making transparent to stakeholders.

For decision makers in the cases outlined, we suggest that the two critical values that need to be balanced are duty to care for patients and personal well-being. We describe each of these values below, and then present a framework that integrates the two. The aim of the framework is to guide the process of balancing these values when staff safety is at stake, to facilitate ethical reflection and decision-making that is systematic, comprehensive and reasoned.

\section{Duty to care for patients}

The notion that health professionals have a role-based obligation to care for patients is fundamental to the functioning of health systems. While the specific extent of this obligation is controversial in various circumstances, ${ }^{15}$ it is generally accepted that health professionals must accept sometimes having to expose themselves to some level of increased risk, burden or inconvenience in order to provide patients with the care they need. ${ }^{16}$

It is helpful to distinguish between duty of care and duty to care as related but different concepts. Duty of care refers to health professionals' legal obligation to adhere to a standard of 
Table 1 Clinical ethics questions and illustrative cases

\begin{tabular}{ll}
\hline Ethical question & Case \\
\hline $\begin{array}{l}\text { Should we decrease patient care } \\
\text { in order to conserve PPE? }\end{array}$ & $\begin{array}{l}\text { 1.David is a nurse caring for a patient who has been hospitalised with suspected COVID-19. The patient is in a single room, awaiting the } \\
\text { COVID-19 test result. This patient has a chronic condition and has had many admissions over the years. In order to conserve the limited PPE } \\
\text { at his hospital, David and his nursing colleagues have been minimising entering the patient's room. The patient is unhappy and is complaining } \\
\text { that the level of nursing care is so different to past admissions. }\end{array}$ \\
$\begin{array}{ll}\text { What should I do when the PPE } \\
\text { provided is inadequate for the }\end{array}$ & $\begin{array}{l}\text { 2.John is a physiotherapist, working in a small regional town. He is on call for the emergency department in the regional base hospital. John } \\
\text { task? }\end{array}$ \\
$\begin{array}{l}\text { has been asked to assist with Celia, a 16-year-old patient with cystic fibrosis, who has come in to ED, feeling increasingly unwell, with increased } \\
\text { normally involves nebuliser therapy and PEP therapy to clear secretions. John is feeling anxious about the level of PPE available to him. He } \\
\text { has only been given a gown and a standard surgical mask. An N95 mask is recommended for aerosol-generating procedures such as airway } \\
\text { clearance, in a patient with respiratory symptoms who has not been cleared of COVID-19. John also does not have access to goggles. }\end{array}$
\end{tabular}

\begin{tabular}{|c|c|}
\hline $\begin{array}{l}\text { Should I abstain from work } \\
\text { protect my family? }\end{array}$ & $\begin{array}{l}\text { 3.James is an infectious diseases registrar scheduled to work in the COVID-19 screening clinic tomorrow. James is fit and healthy, married } \\
\text { and has a } 6 \text {-year-old son. When being briefed about the clinic, he is advised that staff have not worn face shields this past week as they } \\
\text { are currently not available but that they are scheduled to be delivered in 2-3 days' time. James does not wear glasses and is worried about } \\
\text { patients gagging or coughing when the swab is being taken. When he tells his wife, she asks him to call in sick. }\end{array}$ \\
\hline $\begin{array}{l}\text { Can I use more PPE than } \\
\text { recommended, to protect my } \\
\text { vulnerable family member at } \\
\text { home? }\end{array}$ & $\begin{array}{l}\text { 4.Jennifer is an intern working on the wards in a large metropolitan hospital. She lives at home with her mother and elderly grandmother. She } \\
\text { has read in the paper that in some countries that were previously affected by SARS, all doctors routinely wear masks for every interaction wit } \\
\text { every patient. She is about to review a patient with multiple sclerosis who was tested for COVID-19 on admission and is recovering from a } \\
\text { bacterial pneumonia. The patient still has a mild intermittent cough. Jennifer wants to wear a mask as she is worried about her grandmother } \\
\text { who has heart failure. However masks are not recommended when seeing this type of patient and are not easily accessible on the ward. }\end{array}$ \\
\hline $\begin{array}{l}\text { Is wearing the PPE ethically } \\
\text { required when it is inhibiting } \\
\text { my relationship with a low-risk } \\
\text { patient? }\end{array}$ & $\begin{array}{l}\text { 5.Louise is a paediatrician who works with children with autism at a paediatric hospital. Her organisation has mandated the wearing of face } \\
\text { masks by clinicians in her clinic. Louise's view is that the mask is impacting negatively on the care she can provide to patients and isn't really } \\
\text { needed. She knows she has to follow hospital policy but she is worried that the mask will impact on her therapeutic relationship with patient } \\
\text { and families, particularly that it will make it more difficult to establish rapport with the children she treats who often find interpersonal } \\
\text { interactions challenging. She doesn't think that the infection risk to her or to her patients is sufficient to justify wearing the mask. }\end{array}$ \\
\hline $\begin{array}{l}\text { Should we delay resuscitation to } \\
\text { don PPE? }\end{array}$ & $\begin{array}{l}\text { 6.Emily is a 45-year-old consultant in the emergency department. She is well but her husband has rheumatoid arthritis and is on } \\
\text { immunosuppressants. Emily is part of the emergency department planning team. They are planning their approach to resuscitation in the ED, } \\
\text { when the patient's COVID-19 status is unknown. They are considering the scenario of a busy ED where a 50-year-old patient of unknown } \\
\text { COVID-19 status arrests shortly after arrival. All ED staff are wearing surgical masks, but resuscitation is considered a high-risk activity for } \\
\text { transmitting COVID-19 infection and full PPE is recommended. The team are concerned and unsure if the first staff member present should } \\
\text { begin resuscitation, or delay to don additional PPE. Community transmission is currently low, with most confirmed COVID-19 cases from } \\
\text { returned travellers. }\end{array}$ \\
\hline
\end{tabular}

The cases are based on our experiences in Australian hospitals but do not describe specific individuals.

PEP, Positive Expiratory Pressure; PPE, personal protective equipment.

reasonable care. Duty to care, in contrast, is a specifically ethical concept that refers to clinicians' role-based responsibility to provide care to patients even when this involves some degree of burden or risk to the clinician. The term 'duty to treat' is also used for duty to care. ${ }^{12}$ We prefer the term duty to care, as it encompasses all the aspects of healthcare work that are not specifically the provision of medical treatment.

As Malm and colleagues have argued, various grounds for health professionals' duty to care have been put forward including implied consent, special training, reciprocity and professional codes. ${ }^{15}{ }^{17}$ Further, from a principlist perspective, health professionals' duty to care can be conceptualised as based on the ethical principles of beneficence and non-maleficence. In usual circumstances, the duty to care is put into practice by providing care despite feeling tired or frustrated, or despite finding the patient unlikeable or even offensive. In situations of infectious disease, it means caring for patients even though there might some level of risk to health professionals.

The duty to provide patient care is not absolute. Just like all other ethical obligations or values, it needs to be balanced against other ethical considerations. In the context of clinical ethics decisions about PPE, staff members' personal well-being is another crucial ethical consideration.

\section{Personal well-being}

Health professionals' well-being matters. It matters for two reasons. First, health professionals are human beings whose well-being counts as much as everyone else's. Second, health professionals are needed to provide patient care. Particularly in a pandemic, patients will suffer harm if healthcare staff are physically or mentally unable to do their jobs. That is, health professionals are a vital healthcare resource. So health professionals' well-being is both intrinsically and instrumentally valuable.

Health professionals' well-being should be understood broadly, as including both physical health and psychosocial wellbeing. In the context of COVID-19, it is important to protect staff by minimising the risk of infection and by minimising the emotional burdens of clinical work during this public health crisis. Processes for sharing challenging clinical ethics decisions are one important part of minimising these emotional burdens. ${ }^{18}$ Approaches such as the framework below enable decisions to be structured and shared.

As well as including both physical and psychosocial elements, another way in which health professionals' well-being should be understood broadly is by acknowledging that their family members' well-being has an impact. The risk of infecting their own family members has been a key concern for many health professionals working during COVID-19. Some healthcare staff have isolated themselves in separate rooms at home, others have moved to temporary accommodation to avoid infecting immunocompromised family members or sent their children to live with relatives. ${ }^{19-22}$ In a New York Times article, Anna Duarte Valasco, a nurse working in a Barcelona hospital, explained the fear she and her colleagues are facing, and the associated burdens:

'It is terrifying to think that we can be a source of contagion without knowing it. This makes many of us isolate ourselves, 
even from the people who live in our houses. Something that seemed temporary is becoming a way of life, a way of life without kisses, without hugs and without the warmth that we need so much at this moment'. ${ }^{23}$

Concern for loved ones has a significant impact on health professionals, and should be included in the conceptualisation of their well-being.

There is a substantial body of bioethics work recognising the moral value of close family relationships. ${ }^{24}$ As one of us (RJM) has argued elsewhere, having strong intimate relationships in a family is an element of individual flourishing. ${ }^{25}$ Whether conceived in terms of obligations to family members ${ }^{12}$ or intertwined interests of family members, ${ }^{26}{ }^{27}$ keeping their family members well is an important aspect of health professionals' personal well-being.

\section{A framework for structuring clinical ethics decision-making about staff safety}

The following framework provides an approach to balancing duty to care and personal well-being. It provides a structure for individual reflection, collaborative staff discussion and decisionmaking by those responsible for teams, departments and other groups of healthcare staff. It applies specifically to issues of PPE in COVID-19, and also has potential to assist decision makers in other situations involving protection of healthcare staff. The framework is available in a visual format (online supplemental file). ${ }^{28}$

The framework provides a structured approach for coming to an ethically sound decision about limiting or changing patient care in response to concerns about staff safety. There is no algorithm for calculating an ethically appropriate balance between optimal staff protection and optimal patient care. However, using a structured approach will enable situation-specific decision-making. It will also provide a basis for articulating the reasons for a decision, showing what assumptions and judgements were made. This sort of transparency and accountability is particularly important in ethically and emotionally challenging situations like those involving PPE in the COVID-19 pandemic.

Step 1: Characterise the degree of risk to staff as precisely as possible.

a. What is the risk status of the specific patient or patient group?

b. What is the type and length of contact between health professional and patient, and how likely is COVID-19 transmission (or the relevant risk to the health professional) through this route?

There are two elements to characterising the degree of risk to staff: the patient's status and the nature of contact. How much risk would staff actually be exposed to if they were to provide usual nursing care? (case 1); perform Celia's airway clearance wearing a surgical mask rather than an N95 mask? (case 2); work in the COVID-19 clinic without a face shield? (case 3), and so on.

The infection status of the patient is highly relevant in the COVID-19 context. Is the patient or patient group known to be COVID-19-positive, or suspected to be positive based on screening, symptoms, and so on? Are they assumed negative based on screening, symptoms, and so on, or known to be negative? Focussing on the risk status of the patient and the nature of contact enables the degree of risk to the staff member(s) to be identified as precisely as possible. Sometimes perceived risk level may be greater or less than the actual risk.

As is currently the case with COVID-19, there may not always be sufficient evidence to fully quantify different levels of risk. However, a broad objective stratification of risk can be achieved to the degree possible with the information available. For example, with COVID-19, the knowledge we already have about the virus and how it is transmitted provides a basis for a broad stratification of risk.

Step 2: Identify the feasible options for protecting staff, specific to this setting.

a. What are the possible options for protecting staff from the risk in this setting, given available resources?

b. Are there individual staff members with particular vulnerability to the risk?

In this step, the aim is first to identify the full range of possible options for protecting staff by thinking broadly. For example, in the COVID-19 pandemic, various strategies and combinations of strategies are being used to protect staff:

- Using telehealth instead of in-person interactions.

- Physical distancing for in-person interactions.

- Various forms of PPE for staff.

- Patients being fitted with masks or other equipment to reduce risk of transmission to staff.

- Changing methods of doing a procedure, such as the nature or length of contact.

- Deferring or cancelling procedures.

Through discussion, options that were not obvious initially may be generated. The options will, of course, be limited by resource constraints in that setting. In many cases in the COVID-19 pandemic, sourcing additional PPE will simply not be possible.

It is also important to consider the individual situations of the particular staff involved. Clinicians with particular risk factors (eg, existing medical conditions, being immunosuppressed, age) need to have their individual situation taken into account. The degree of risk to some staff members may be greater than to others. Options such as particular staff stepping aside from some procedures or interactions are appropriate to consider.

Further, differing levels of individual anxiety or tolerance for risk are also appropriate to take into account. Different health professionals will interpret their duty to care more or less expansively, and accommodating this to some extent is ethically appropriate. As Rosenbaum writes, 'the point at which sacrifice (made by health staff) becomes self-sabotage is different for everyone'. ${ }^{29}$ Individual differences in biomedical risk factors, psychosocial situation and family vulnerability are appropriate to consider, given the conceptual understanding of personal well-being described earlier.

Step 3: For each option, identify the degree of protection afforded to staff and the impact on the patient

a. How much protection does this option offer staff?

b. What is the effect on the patient or patient group that would follow from implementing this option?

At this point in the decision-making process, there will be a set of feasible options for protecting the individual clinician or team from the specified risk. For each option, it is important to consider the impact on staff safety and the potential detriment to patient care that would result from implementing this option. Assessing the impact on patients includes attention to their immediate physical health, and to their psychosocial wellbeing and the long-term impacts of not getting the usual care at the usual time.

Step 4: Look for the option or options that have a proportionate effect on patient care.

a. Does the option make a meaningful difference to staff well-being? 
b. Is the decrease or change required in patient care proportionate to the increase in staff safety from that option?

c. Does another option provide (almost as much) protection for staff, with less detrimental impact for patients?

The aim in this step is to find the option (or options) that optimally balance the two values of duty to care and staff well-being. Options that involve a disproportionately detrimental effect on patients need to be avoided. Coming to a good ethical decision requires a combination of creative and careful systematic thinking. It is very important to look at all the feasible options before settling on an acceptable compromise between the two values.

Step 5: Note the conditions that would prompt a review of the decision.

a. What changes to the clinical situation would require the decision to be reviewed?

b. What new information or evidence would require the decision to be reviewed?

c. What changes to staff members' individual circumstances would require the decision to be reviewed?

Healthcare situations can change quickly. In the COVID-19 pandemic, for example, a surge of affected patients would change the available resources; a situation could evolve from one of adequate PPE to one of inadequate PPE rapidly. Therefore it is important to articulate the conditions that would require a decision be revisited. These might be changes to the clinical situation or to staff members' circumstances. The emergence of new information might also substantially change the justifiability of an ethical decision. For decision makers balancing staff wellbeing and patient care, it is important to consider what additional information or evidence would make a crucial difference. Incorporating conditions and a mechanism for review increases the rigour of the decision-making process. ${ }^{163031}$

\section{The framework applied to a case}

Case 6 outlined earlier (Should we delay resuscitation to don PPE?) can be used to explore how the framework would apply to a specific situation. Recall Emily, an emergency department consultant, whose husband was immunosuppressed. How would the framework assist Emily's ethical reflection and her contribution to decision-making in her team?

Step 1 asks Emily to characterise the degree of risk to staff as precisely as possible. Emily and her colleagues would need to talk to the infectious diseases team in her hospital, for up-todate evidence and information. Focusing on the risk status of the specific patient or group of patients would prompt consideration of a range of factors potentially relevant to patients requiring resuscitation in the ED: the presence of symptoms suggestive of COVID-19, risk factors such as recent travel or being a close contact of a COVID-19 positive patient and current levels of community transmission of the virus. Thinking about the contact required to resuscitate a patient identifies that the length of contact is sustained-greater than 15 min-and the type of contact is extremely close with a high volume of aerosol particles generated. If the patient was infected, resuscitation is a high-risk activity. In Emily's situation however, community transmission is currently low with most confirmed COVID-19 cases from returned travellers. The actual risk to staff may be different to the perceived risk, hence the need to liaise with the relevant experts within the hospital in order to characterise the degree of risk to staff performing resuscitation, as accurately as the current evidence will allow.

Step 2 asks Emily to identify the feasible options for protecting staff, specific to this setting. Discussing options with colleagues will likely generate a range of ideas. In this situation, options might include (A) The whole resuscitation team donning full PPE and then commencing CPR, (B) The first team member starting CPR while the other staff don full PPE, and (C) The resuscitation team performing CPR and related resuscitation activities without full PPE. The framework directs decision makers to consider the possible options for protecting staff in this setting, meaning that issues such as the current availability and distribution of PPE in Emily's hospital will have an impact on the development of options. The framework also directs decision makers' attention to individual staff members who may have a particular vulnerability to the risk being discussed. In line with the conceptualisation of personal well-being outlined earlier, this should include staff members' own health vulnerabilities and the vulnerabilities of family members. In Emily's case, she has a particular vulnerability: her husband's immunosuppression should be taken into account when decisions are made about how to approach resuscitation in her working environment. Other ED staff may also have vulnerabilities that need to be taken into account; this step prompts attention to staff members' individual situations.

Step 3 directs Emily and her colleagues to identify the degree of protection afforded to staff for each option, and the impact on patients. Potential examples are summarised in table 2. The table is intended to indicate how the framework structures reflection and decision-making, rather than to make an argument that a particular option is the ethically appropriate one in Emily's case; context-specific factors will influence the ethically appropriate option in any actual situation.

Step 4 focuses on proportionality; the aim is to identify the option that makes a meaningful difference to staff well-being while minimising impact on patient care. The impact on staff

Table 2 Example options for case 6

\begin{tabular}{|c|c|c|}
\hline Options & Impact on staff & Impact on patients \\
\hline $\begin{array}{l}\text { A. Whole resuscitation team dons full } \\
\text { PPE prior to commencing resuscitation }\end{array}$ & Effectively protects staff & $\begin{array}{l}\text { Significant delay commencing resuscitation; poorer health outcomes } \\
\text { including worse neurological outcome and increased risk of death }\end{array}$ \\
\hline $\begin{array}{l}\text { B. First team member starts } \\
\text { resuscitation while others don full PPE }\end{array}$ & $\begin{array}{l}\text { Risk of infection (degree as characterised in step 1) to first staff } \\
\text { member. } \\
\text { Increased responsibility for first staff member in relation to } \\
\text { patient's outcome- that is, greater psychosocial burden to staff } \\
\text { member }\end{array}$ & $\begin{array}{l}\text { Minimal delay commencing resuscitation, but possible decreased } \\
\text { efficacy given other staff members delayed; patient health outcomes } \\
\text { likely worse than A but better than C }\end{array}$ \\
\hline $\begin{array}{l}\text { C. Team begins resuscitation without } \\
\text { donning full PPE }\end{array}$ & $\begin{array}{l}\text { Risk of infection (degree as characterised in step 1) to all staff } \\
\text { members }\end{array}$ & $\begin{array}{l}\text { Maximises patient's chances of resuscitation and minimises } \\
\text { neurological damage } \\
\text { If any staff member is unknowingly COVID-19 positive, risk of } \\
\text { infecting patient }\end{array}$ \\
\hline
\end{tabular}


should be proportional to the impact on patients. This type of ethical balancing is not formulaic, and most rigorously achieved through group discussion. Emily's process should be one of ethical reflection and discussion with colleagues.

Once they have reached a settled view, step 5 asks them to articulate conditions which would require review of their decision. For example, in this case, relevant changes might be a significant increase in the level of community transmission, new evidence that affects the risk characterisation in step 1, or a change in Emily's husband's health status or treatment. Throughout the process, consideration of the team's role within the broader hospital and the need to engage with others in the organisation (such as quality and safety structures, COVID-19 response coordinators, etc) and ensure alignment with hospitalwide decisions and policies will be important.

\section{CONCLUSION}

This five-step structured approach means that each clinician or leader would work with their colleagues to identify risks and available options, and then to weigh up their ethical significance and impact. This equates to what Battin calls bringing moral reasoning to bear. ${ }^{32}$ It represents a crucial skill to meet the challenges of COVID-19 and beyond.

Limiting or changing patient care to protect staff is difficult for everyone. It is distressing both for patients and health professionals to encounter situations, like COVID-19, that impinge on usual provision of care to patients. Using a structured approach to ethical decision-making in this type of situation can promote both rigour and transparency, increasing the quality and visibility of reasoning. It is crucial that health professionals are supported to navigate these ethical decisions about staff protection, and to communicate the basis on which these difficult decisions have been made.

\section{Twitter Rosalind J McDougall @ethicsros}

Acknowledgements The authors thank Charlotte Barr for her contribution to developing one of the cases outlined in the paper, and to Alana Pirrone for her design assistance on the visual summary of the ethical framework for health service use (online supplemental file).

Contributors RJM, CD and LG conceptualised the paper. RJM and LG wrote the first draft. CD, DK and IH made substantial revisions.

Funding The project was funded by the Centre for Health Equity COVID-19 Small Grant Scheme, at the University of Melbourne.

Competing interests None declared.

Patient consent for publication Not required.

Provenance and peer review Not commissioned; externally peer reviewed.

Data availability statement There are no data in this work.

This article is made freely available for use in accordance with BMJ's website terms and conditions for the duration of the covid-19 pandemic or until otherwise determined by BMJ. You may use, download and print the article for any lawful, non-commercial purpose (including text and data mining) provided that all copyright notices and trade marks are retained.

\section{ORCID iDs}

Rosalind J McDougall http://orcid.org/0000-0002-3809-2575

Isabella Holmes http://orcid.org/0000-0002-5822-7561

\section{REFERENCES}

1 ABC News. Coronavirus doctors report trauma, threats over lack of PPE in hospitals. Available: https://www.abc.net.au/news/2020-04-09/coronavirus-doctors-trauma-asppe-equipment-sharing-re-use/12136692 [Accessed 25 May 2020].
2 The Guardian. NHS staff making masks from snorkels amid PPE shortages, 2020. Available: https://www.theguardian.com/society/2020/apr/01/nhs-staff-makingmasks-from-snorkels-amid-ppe-shortages [Accessed 25 May 2020].

3 The New Yorker. How did the U.S. end up with nurses wearing garbage bags? Available: https://www.newyorker.com/news/letter-from-trumps-washington/thecoronavirus-and-how-the-united-states-ended-up-with-nurses-wearing-garbage-bags [Accessed 25 May 2020].

4 Dwyer J, Tsai DF-C. Developing the duty to treat: HIV, SARS, and the next epidemic. J Med Ethics 2008;34(1):7-10.

5 Emanuel EJ. The lessons of SARS. Ann Intern Med 2003:139(7):589-91.

6 Fenton E. Personal protective equipment for front-line health workers: an ethical imperative, 2020. JME Blog. Available: https://blogs.bmj.com/medical-ethics/2020/03/ 31/personal-protective-equipment-for-front-line-health-workers-an-ethical-imperative/ [Accessed 3 Jun 2020].

7 Schuklenk U. Healthcare professionals are under no ethical obligation to treat COVID-19 patients. JME Blog, 2020. Available: https://blogs.bmj.com/medical-ethics/ 2020/04/01/health-care-professionals-are-under-no-ethical-obligation-to-treat-covid19-patients/ [Accessed 3 Jun 2020].

8 Hauser T. Rewarding through prioritization: the limits of reciprocal obligation in allocating scarce medical resources in the COVID-19 crisis. JME Blog, 2020. Available: https://blogs.bmi.com/medical-ethics/2020/04/09/rewarding-through-prioritizationthe-limits-of-reciprocal-obligation-in-allocating-scarce-medical-resources-in-thecovid-19-crisis/?int_source=trendmd\&int_campaign=usage-042019\&int_medium= cpc [Accessed 3 Jun 2020].

9 News ABC. GPs under coronavirus pressure with masks in short supply and fears of what is to come, 2020. Available: https://www.abc.net.au/news/2020 -03-24/gpsunder-intense-coronavirus-pressure-ppe-maskshortage/12082404 [Accessed 25 May 2020].

10 RACGP. New PPE supplies 'critical' for overcoming pandemic, 2020. Available: https:// www1.racgp.org.au/newsgp/professional/new-ppe-supplies-critical-for-overcomingpandemic [Accessed 25 May 2020].

11 ABC Four Corners. Flattening the curve, 2020. Available: https://www.abc.net.au/ 4corners/flattening-the-curve/12213508 [Accessed 25 May 2020].

$12 \mathrm{McC}$ Connell D. Balancing the duty to treat with the duty to family in the context of the COVID-19 pandemic. J Med Ethics 2020;46(6):360-3.

13 Dunn M, Sheehan M, Hordern J, et al. 'Your country needs you': the ethics of allocating staff to high-risk clinical roles in the management of patients with COVID-19. J Med Ethics 2020;46(7):436-40.

14 McDougall R, Shadbolt C, Gillam L. The practice of balancing in clinical ethics case consultation. Clin Ethics 2020:15(1):49-55.

15 Malm H, May T, Francis LP, et al. Ethics, pandemics, and the duty to treat. Am J Bioeth 2008:8(8):4-19.

16 Thompson AK, Faith K, Gibson JL, et al. Pandemic influenza preparedness: an ethical framework to guide decision-making. BMC Med Ethics 2006;7(1):12.

17 Ruderman C, Tracy CS, Bensimon CM, et al. On pandemics and the duty to care: whose duty? who cares? BMC Med Ethics 2006;7(5):5.

18 Nussbaum M. Therapeutic arguments. In: Nussbaum M, ed. The therapy of desire. Princeton University Press: Princeton, 2009.

19 ABC News. NSW healthcare workers struggling to keep families safe from coronavirus, 2020. Available: https://www.abc.net.au/news/2020-04-02/nsw-healthcare-workersleaving-families-in-coronavirus-crisis/12111218 [Accessed 25 May 2020].

20 ABC News. Healthcare workers leaving home and family to continue fight against coronavirus. Available: https://www.abc.net.au/news/2020-05-12/healthcare-workers moving-out-of-home-to-fight-coronavirus/12168032 [Accessed 25 May 2020].

21 The Guardian. US medical workers self-isolate amid fears of bringing coronavirus home, 2020. Available: https://www.theguardian.com/world/2020/mar/19/medicalworkers-self-isolate-home-fears-coronavirus [Accessed 25 May 2020].

22 The Sun. I've sent my daughter away so I don't infect her while working as an A\&E nurse \& I don't know when I'Il see her again. Available: https://www.thesun.co.uk/ news/11301100/coronavirus-nhs-nurse-diary-ventilators-doorstep/ [Accessed 25 May 2020].

23 The New York Times. In Harm's Way. Available: https://www.nytimes.com/interactive/ 2020/world/coronavirus-health-care-workers.html\#item-anna-duarte-velasco [Accessed 25 May 2020].

24 Lindemann Nelson H, Lindemann Nelson J. The patient in the family: an ethics of medicine and families. New York: Routledge, 1995

25 McDougall R. Can families have interests? Am J Bioeth 2017:17(11):27-9.

26 Groll D. Four models of family interests. Pediatrics 2014;134 Suppl 2:S81-6.

27 Lindemann H. Why families matter. Pediatrics 2014;134 Suppl 2:S97-103.

28 McDougall R, Gillam L, Ko D, et al. An ethical framework for decision-making about staff safety. Available: https://mspgh.unimelb.edu.au/centres-institutes/centre-forhealth-equity/research/che-covid-19/an-ethical-framework-for-decision [Accessed 27 Aug 2020].

29 Rosenbaum L. Once upon a time... the hero sheltered in place. N Engl J Med 2020;383(2).

30 Daniels N. Accountability for reasonableness. BMJ 2000;321(7272):1300-1.

31 Gibson JL, Martin DK, Singer PA. Priority setting in hospitals: Fairness, inclusiveness, and the problem of institutional power differences. Soc Sci Med 2005;61(11):2355-62.

32 Battin MP. Bioethics. In: Lafollette H, ed. International encyclopedia of ethics, 2013. 